Educación Física y Ciencia, vol. 20, n 1, e041, 2018. ISSN 2314-2561

Universidad Nacional de La Plata.

Facultad de Humanidades y Ciencias de la Educación.

Departamento de Educación Física

\title{
Inclusão escolar de alunos com deficiência: interface com os conteúdos da Educação Física
}

Carvalho, Camila Lopes de; Araújo, Paulo Ferreira de

Cita sugerida: Carvalho, C. L. y Araújo, P. F (2018). Inclusão escolar de alunos com deficiência: interface com os conteúdos da Educação Física. Educación Física y Ciencia, 20(1), e041. https://doi.org/10.24215/23142561e041 
Inclusão escolar de alunos com deficiência: interface com os conteúdos da Educação Física

Inclusion of school students with disabilities: interface with the contents of Physical Education

Camila Lopes de Carvalho

Faculdade de Educação Física, Universidade Estadual de

Campinas, Brasil

camilalopes.c@hotmail.com

Paulo Ferreira de Araújo

Faculdade de Educą̧ão Física, Universidade Estadual de

Campinas, Brasil

paulof@fef.unicamp.br

\section{Resumo:}

Nas últimas décadas, a Educação Física brasileira foi redefinida em seus objetivos, finalidades, conteúdos e atuações no cenário escolar, ao mesmo tempo no qual passou a incorporar os ideais inclusivos estabelecidos socialmente. Dessa forma, o objetivo desse estudo foi analisar o processo de inclusão de alunos com deficiência na Educação Física Escolar no contexto brasileiro, perante seus principais conteúdos, conforme estabelecido pelo movimento renovador da área - Dança, Esporte, Ginástica, Jogo e Luta. Para isso, foi realizada uma pesquisa qualitativa, composta por um estudo de caso, no qual as aulas de Educação Física de uma turma do $2^{\circ}$ ano do ensino fundamental I, que possuiu dois alunos com deficiência, foram observadas durante 1 ano letivo, com análise de dados por categorização. Foi verificada uma predominância de aspectos positivos à inclusão (maioria de participações ativas e interações positivas entre todos nas aulas), mas entremeados por outros negativos (superioridade de aulas dos conteúdos de Jogo e Esporte sobre os demais, e interações negativas em atividades de caráter competitivo e técnico). Concluindo, tem ocorrido uma construção positiva em direção à Educação Física inclusiva, mas que ainda necessita de maior capacitação docente para explorar os diversos conteúdos desta área durante as aulas, associando-os às práticas de inclusão.

Palavras-CHAVE: Educação Especial, Educação Inclusiva, Educação Física Escolar.

\section{Abstract:}

Physical Education has been redefined in recent decades, its objectives, aims, contents and performances at school, at the same time, that it has incorporated ideas of inclusion socially established. Thus, the aim of this study is to analyze the process of inclusion of students with disabilities in Physical Education in their main content. Therefore, a qualitative survey was conducted, consisting of a case study, where lessons of physical education in a class of 2 nd year of elementary school, which has two students with disabilities, were observed for 1 school year, with data analysis by categorization. A predominance of positive aspects to the inclusion was seen (active participation and positive interactions among all the classes), but intermingled with other negative (Game and Sports over others contents, and negative interactions in competitive and technical activities). In conclusion, there is a positive construction of inclusive physical education at schools but there is a need for more professional training to explore the different contents of Physical Education and associate them to inclusive education.

KEYWORDS: Special Education, Inclusive Education, Physical Education.

\section{INTRODUÇÃO}

A partir da $2^{\circ}$ Guerra Mundial as questões referentes aos direitos humanos passaram a permear as discussões sociais em diversos países, despontando de forma impulsionada, principalmente, pela Declaração Universal dos Direitos Humanos, proclamada pela Organização das Nações Unidas (ONU), em 1948, publicação que discorreu sobre a necessidade de todas as pessoas serem consideradas iguais perante a Lei (ONU, 1948).

Segundo Kassar (2011), com esse documento beneficiando os grupos minoritários, também foi incitado o estabelecimento de ações políticas mundiais concernentes, especificamente, às pessoas com deficiência. Por conseguinte, atos políticos e sociais explicitaram sobre a garantia dos direitos dessa população, incluindo 
o direito à educação. Dentre essas ações instigadoras, a Lei Pública 94-142, de 1973, "Education for all handicapped chindren act" ("Educação para todas as crianças deficientes"), dos Estados Unidos, e o Relatório de Warnock, de 1978, da Inglaterra, principiaram o objetivo de inserir alunos com necessidades educativas especiais nas escolas regulares. Já a Declaração de Cuenca, elaborada em 1981, defendeu o atendimento educacional de qualidade às pessoas com deficiência; a Declaração Mundial sobre Educação para Todos, publicada em 1990, em Jomtiem, na Tailândia, convocou os países a ofertarem acesso às pessoas com deficiência ao sistema educativo; e a Declaração de Salamanca, apresentada em 1994, durante a "Conferência Mundial de Educação Especial”, na Espanha, propôs que as nações adotassem uma educação inclusiva, na qual as escolas se adaptassem para proporcionar a mesma qualidade de ensino a todos os alunos, independente de suas diferenças ou dificuldades (Silva, 1987; Brasil, 1994; Meireles-Coelho, Izquierdo \& Santos, 2007).

Dessa forma, as pessoas com deficiência transitaram de um período de exclusão para uma fase de construção de políticas para a sua aceitação e participação na sociedade. Conforme panorama apresentado por Jannuzzi (1992), na antiguidade pessoas com essas condições foram abandonadas, rejeitadas e até mesmo condenadas à morte devido à deficiência ser atribuídas a fatores sobrenaturais como pecado cometidos em vidas anteriores ou presença de um mau espírito. Com a expansão do cristianismo a partir da idade média, essas pessoas começaram a ser vistas possuidoras de almas, em uma propagação da necessidade de todos serem caridosos com elas como forma de alcance do perdão divino e da vida eterna; dessa forma não poderiam ser eliminadas, sendo institucionalizadas em asilos, conventos, igrejas e manicômios afastados da cidade que garantiam sua sobrevivência, ainda que isoladas.

Somente na idade moderna, a preocupação com o cuidado e a educação das pessoas com deficiência abdicaram de maior espaço e consideração, em direção à construção da sua aceitação na sociedade. Na década de 1950, o princípio da normalização surgiu como um dos eixos norteadores da educação da pessoa com deficiência visando as proporcionar um padrão de vida semelhante ao vivenciado na sociedade, contudo ainda dentro de instituições especiais; na sequência, um ideal de integração despontou, objetivando prepará-las para serem inseridas socialmente; e, por fim, na década de 1980 o paradigma inclusivo trouxe o entendimento de que a sociedade é que deveria se adaptar para receber e permitir a participação de todos em suas estruturas e funções (Silva, Seabra Junior \& Araújo, 2008).

Apesar de propostos em momentos distintos, e do vigente entendimento de ser o terceiro paradigma o adequado para o momento atual, todos os três ideais permaneceram coexistindo, pela dificuldade de cada um deles superar totalmente o precedente.

O então ideal inclusivo atualmente almejado para se consolidar se desenvolveu por meio da associação de movimentos populares - que defendiam os direitos dessa população, compostos principalmente por familiares dessas pessoas - aos novos modelos político-econômicos capitalistas implantados e instigados pelos países desenvolvidos a serem seguidos pelos demais - os quais viam na pessoa com deficiência um contribuidor ao desenvolvimento social e econômico, ao serem capazes de atuar como produtores e consumidores ativos na sociedade.

Essas ações se refletiram no Estado Brasileiro, o qual infundiu os ideais inclusivos em sua legislação. Inicialmente, a Constituição de 1988, ainda fundamentada em ideais integracionistas, possibilitou a inserção da pessoa com deficiência na escola regular; já pela Lei de Diretrizes e Bases da Educação (LDB), de 1996, a educação especial foi redefinida como uma educação a ser oferecida às pessoas com deficiência preferencialmente na rede regular de ensino, contando com adequação e capacitação da estrutura e agentes educacionais; fundamentados nessas duas promulgações principais, documentos seguintes foram elaborados para especificar e conduzir a educação brasileira em uma perspectiva inclusiva, como is Planos Nacionais de Educação de 2001 e 2014 (Brasil, 1988, 1996, 2001a, 2014).

De forma concomitante, a legislação brasileira confirmou a Educação Física como um dos componentes curriculares obrigatórios do ensino básico nacional, pela Lei $n^{\circ} 10.328$, de 2001, exigindo sua adequação aos ideais inclusivos estabelecidos (Brasil, 20001b). 
Nesse mesmo período, seus objetivos, finalidades e funções estavam sendo repensados e reconstruídos academicamente. Retomando brevemente a sua constituição no cenário nacional, a Educação física foi inserida oficialmente no currículo escolar brasileiro por meio de uma sugestão da Reforma Couta Ferraz, em 1851, por meio da qual foi explorada nas escolas, inicialmente, fundamentada em Métodos Ginásticos Europeus, devido à influência político-econômica desse território sobre o país. No Brasil, esses Métodos foram recebidos por diferentes segmentos que o exploraram segundo seus interesses: políticos e militares os direcionaram para disciplinar o corpo físico e a moral, visando a manutenção da ordem política e o preparo físico para força de trabalho; os médicos os associaram aos cuidados higiênicos objetivando um progresso civilizatório pela formação de uma população forte e saudável; e uma parcela de educadores enfatizavam sua atuação destinada à formação humana. Assim, as atividades da área, nas décadas seguintes, organizaramse sustentadas por exercícios técnicos motores e treinamentos esportivos visionários do alto rendimento (Castellani Filho, 1991; Linhares, 2009; Góis Junior, 2013).

Com questionamento a essa forma de atuação da área, propostas foram elaboradas em uma tentativa de ressignificar a área, reformulando seus objetivos, finalidades e funções, substituindo o foco na aptidão física para a construção de conhecimento sobre suas práticas abarcadas pelas diferentes dimensões humanas, como a afetiva, psicológica e a sociocultural, dentre outras, denominadas de Teorias ou Abordagens da Educação Física.

Nessa conjuntura, destacaram-se no contexto acadêmico brasileiro o Coletivo de Autores (1992) e os Parâmetros Curriculares Nacionais (PCN) (Brasil, 1998).

O Coletivo de Autores foi uma autodenominação dos autores do Livro "Metodologia do Ensino de Educação Física”, publicado em 1992, por Micheli Ortega Escobar, Elizabeth Varjal, Valter Bracht, Celi Taffarel, Carmen Lúcia Soares e Lino Castellani Filho, com uma proposta sobre o objetivo do ensino da Educação Física Escolar a partir de uma visão crítico-superadora, na qual a área de conhecimento da Educação Física foi definida como a referente à cultura corporal. Inaugurou reflexões até então não sistematizadas para a área, baseadas na visão crítico social a qual já dispendia de influências no cenário pedagógico brasileiro, mas que ainda ausentava-se na Educação Física nacional. Com isso, estabeleceu-se como uma das bases principais para as construções de conhecimento da área que viriam na sequência.

Já os PCN foram elaborados como uma orientação política de caráter nacional para a organização dos currículos das disciplinas escolares, associando os conhecimentos acadêmicos já produzidos com uma organização prática no contexto escolar. Esses documentos foram publicados em três blocos: em 1997 destinado ao ensino fundamental I, em 1998 ao ensino fundamental II e, em 1999, ao ensino médio.

Ao entender a relevância brasileira de ambos ao instituírem uma inicial construção de conhecimentos e orientações de caráter prático, os quais estimularam e fundamentaram as construções posteriores da ciência e da atuação da Educação Física, nesse estudo esses referenciais foram considerados como orientadores das reflexões dispendidas. Não se pretende propor ou instigar uma concordância absoluta com tais documentos, uma vez que, segundo Souza Júnior (2011) os próprios autores divergiram entre si em relação a algumas temáticas ou especificidades conceituais, mas um respeito e consideração pela importância de ambos ao organizarem e estruturarem cientificamente e politicamente a área no Brasil, em um momento no qual a Educação Física ainda caminhava por um período de crise com objetivos e atuação isentos de finalidade própria.

Em diálogo com essas produções, os conteúdos que compõe a Educação Física foram definidos como aqueles compostos por movimentos corporais construídos e transformados pelo homem durante o decorrer histórico como forma de representação de sua realidade, com significação humana e sociocultural, sendo os principais Dança / Atividades Rítmicas e Expressivas, Esporte, Ginástica, Jogo e Luta (Coletivo de autores, 1992; Brasil, 1998): 
Averígua-se que, por orientações legais, a Educação Física atua no ensino básico brasileiro por meio de uma organização prática fundamentada na exploração de cinco principais conteúdos, os quais são explorados por uma orientação pedagógica inclusivista.

Contudo, Manzini (2002) alertou que apenas razões legais assegurando a matrícula do aluno com deficiência na escola regular não garantem a prática da inclusão nas aulas das diversas disciplinas do currículo escolar, com a Educação Física e seus conteúdos, nesse caso.

Para o acompanhamento dessa realidade, estudos acadêmicos tem sido produzidos acerca da temática da inclusão na Educação Física Escolar brasileira, mas, em sua maioria, de forma pontual, como sobre a formação dos professores já em atuação ou a interação social dos alunos. Estes são relevantes, mas podem camuflar aspectos influenciadores dos resultados encontrados. É sentida a ausência da análise da inclusão global na Educação Física Escolar, considerando a construção inclusiva da área de forma relacionada a sua própria organização pedagógica.

Fundamentado nesse contexto, questiona-se como está ocorrendo a implantação do processo de inclusão de alunos com deficiência, imposto legalmente no Brasil, em interface com a busca pela efetivação de uma prática reconstruída em seus objetivos e finalidades, nas últimas décadas. Por conseguinte, esse estudo tem por objetivo analisar o processo de inclusão de alunos com deficiência na Educação Física Escolar, perante seus diferentes conteúdos - Jogo, Esporte, Ginástica, Luta e Dança.

\section{Metodologia}

Esse estudo foi delineado como uma pesquisa de natureza qualitativa, na qual a coleta dos dados ocorreu de forma direta no seu ambiente natural por meio de um pesquisador, dados estes de natureza predominantemente descritiva. O mesmo foi desenvolvido por meio de um estudo de caso, no qual um grupo foi delimitado dentro de um ambiente amplo para ter suas características investigadas, visando uma compreensão de dada realidade e sua possível forma de ocorrência na sociedade (Ludke \& André, 1986).

Como procedimentos metodológicos, após encaminhamento e aprovação da pesquisa pelo Comitê de Ética da Universidade Estadual de Campinas, com número de parecer 166.688, foram observadas as aulas de Educação Física de uma sala do $2^{\circ}$ ano do ensino fundamental I, de uma escola particular do município de Americana, no estado de São Paulo, Brasil, composta por 26 alunos dos quais dois apresentavam condições de deficiência - Síndrome de Down. As observações ocorreram durante 1 ano letivo, totalizando 71,4 \% de aulas acompanhadas; o restante de $28,6 \%$ de aulas não acompanhadas foram canceladas ou substituídas por atividades escolares extra disciplinares - como excursões e eventos escolares.

Ao final de cada aula observada, o pesquisador a analisou sob o prisma da inclusão por meio do preenchimento do "Instrumento de avaliação da interação entre alunos com e sem deficiência na educação física escolar”, de Salerno, Araújo e Silva (Salerno, 2009). Tal instrumento passou por validação de face e semântica, confirmando o alcance das finalidades às quais se propôs. É composto pelos cinco eixos temáticos com itens analisados quanto a sua ocorrência ou não, sendo eles "Acessibilidade", "Conteúdos da Educação Física", "Atitudes e estratégias do professor durante o tempo das aulas", "Atitude do aluno com deficiência" e "Atitude dos alunos sem deficiência".

Os dados coletados foram analisados por categorização a qual, segundo Ludke e André (1986), referese à organização dos dados em categorias ou temas de análise, buscando não apenas uma descrição, mas possibilitando sua interpretação e a identificação de novos questionamentos. Dessa forma, foram construídas as categorias de "Acessibilidade", "Conteúdos trabalhados" e "Aspectos inclusivos durante as aulas dos diferentes conteúdos". 


\section{REsultados E Discussões}

Os resultados encontrados estão apresentados e discutidos abaixo:

\section{Acessibilidade}

A Lei brasileira $n^{\circ} 10.098$, de 2000, definiu acessibilidade à pessoa com deficiência como "possibilidade e condição de alcance para utilização, com segurança e autonomia, dos espaços, mobiliários e equipamentos urbanos, das edificações, dos transportes e dos sistemas e meios de comunicação", estabelecendo normas e critérios para promovê-la em todos os espaços e equipamentos públicos nacionais (Brasil, 2000, p. 01).

Uma análise quanto à acessibilidade da estrutura escolar tornou-se pertinente uma vez que ela influencia o acesso inicial e a possibilidade dos alunos usufruírem das disciplinas escolares e seus conteúdos de forma permanente.

Assim, a instituição em questão possuía os itens de acessibilidade mais comumente encontrados: corrimões nas escadas e banheiros adaptados. Contudo, alguns itens atuantes como possíveis barreiras permaneceram, como a presença de escadas pelo ambiente sem a existência de outra possibilidade de acesso, além da ausência de sinais visuais e sonoros.

Essa fragilidade estrutural também foi verificada por Gorgatti e Rose Junior (2009), os quais evidenciaram, em uma pesquisa com professores de escolas particulares e públicas do Brasil, que todos afirmaram que suas instituições ainda não estavam totalmente preparadas quanto a sua estrutura de acessibilidade para a recepção de alunos com deficiência.

Tal ocorrência foi justificada pelo estudo de Mazzarino, Falkenbach e Rissi (2011), o qual afirmou que a adaptação de locais e equipamentos tem sido feita apenas a partir do momento no qual uma pessoa com uma condição específica de deficiência inicia a utilização destes, e não de forma antecipatória à presença dessa população. Uma alteração nesse processo de adaptação estrutural mostra-se necessária, adequando a instituição antecipadamente para a recepção de alunos com qualquer que seja a sua característica, conforme garantido legalmente.

\section{Conteúdos trabalhados}

Nas escolas brasileiras, é definido quantitativamente, para a disciplina de Educação Física, a realização de duas aulas semanais de 50 minutos cada. Na instituição observada, cada aula foi ministrada de forma dupla, ou seja, foi contabilizado nesse estudo uma aula de 1 hora e 40 minutos, uma vez que o professor a organizou como aulas conjuntas de uma só temática, ao invés de duas aulas de 50 minutos: 


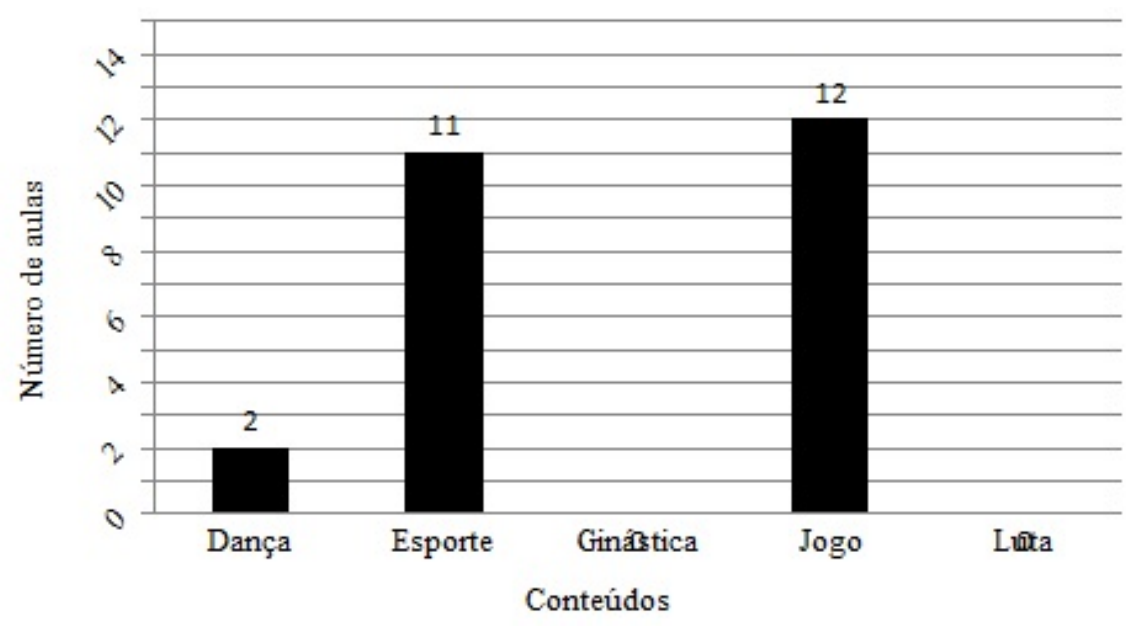

Gráfico 1 - Número de aulas destinadas a cada conteúdo da educação física.

A presença exacerbada dos conteúdos de Jogo e Esporte é notória. Enquanto Dança obteve menor contemplação durante o período letivo, a Ginástica e a Luta não apareceram.

Apesar da redefinição educacional para a Educação Física, observa-se uma permanente dificuldade, por parte do professor, em trabalhar as diferentes temáticas propostas, permanecendo arraigado à prática passada.

Essa dificuldade também foi verificada no estudo de Seabra Junior (2006), o qual mostrou que a influência das novas teorias da Educação Física sobre a prática real do professor está em construção, com ainda persistência de aulas orientadas pelo conteúdo de Esporte ou pelo desenvolvimento de habilidades motoras esportivas.

Vários fatores podem ser elencados como precursores desse tipo de ocorrência, como a construção histórica brasileira de uma Educação Física com ênfase na aptidão física e nas habilidades esportivas, a falta de segurança dos próprios professores em abordarem os diferentes conteúdos numa formação acadêmica nem sempre com qualidade para uma atuação adequada com estes, uma questão sociocultural na qual muitas vezes os próprios alunos rejeitam os novos conteúdos com os quais não estão habituados por receio do novo, além de, segundo Silva, Seabra Junior e Araújo (2008), a estrutura e funcionamento da própria escola que, em muitos casos, restringe o trabalho dos professores, como ao exigir quantidade excessiva de tempo para a organização de eventos esportivos.

Como falar em inclusão nos diferentes conteúdos da Educação Física se parte destes temas ainda é negado aos alunos? Nesse aspecto a inclusão esbarra não nos aspectos referentes às necessidades dos alunos com deficiências, mas na estrutura da aula, a qual não comtempla a diversidade de práticas, negando aos alunos o direito de vivência e conhecimento dos diversos elementos da cultura corporal abarcados por essa disciplina.

Em relação á Luta, Correia e Franchini (2010) afirmaram que a escassez do seu ensino no contexto escolar deve-se às precariedades na formação inicial, a qual não tem explorado sua variedade de possibilidades de aplicações pedagógicas de forma adequada. Tal ocorrência, muitas vezes é ocasionada pela presença de um discente que assume a disciplina por ter vivência prática com apenas uma modalidade da Luta, mas desprovido de conhecimentos sobre sua variedade de práticas e de sua organização pedagógica. Os autores completaram ainda que a pequena quantidade de construção de pesquisas científicas a esse respeito tem contribuído com a manutenção dessas dificuldades para sua implantação na realidade escolar, uma vez que o estudo acadêmico é a base para a futura atuação profissional.

Ayoub (2003) e Carvalho, Darido e Impolcetto (2015) corroboraram a discussão sobre a precariedade na exploração dos diferentes temas da Educação Física ao apontar que a escassez de propostas e orientações pedagógicas dificulta a organização também da Ginástica no contexto educacional. Refletiram que esses 
conteúdos são sucumbidos a um desprestígio dentro da Educação Física Escolar brasileira, a qual, quando explora essas opções temáticas, as trabalhada desprovida de suas bases histórico-culturais, sendo submetida à ideais esportivizantes.

Sabendo que a superioridade do Esporte também é apresentada na área acadêmica brasileira, conforme demonstrado por Matos Schneider, Mello, Ferreira Neto \& Santos (2013), os quais observaram que este conteúdo se mantém em evidência em quantidade dentre os demais nas publicações dos periódicos nacionais, denota-se a indispensável necessidade de uma reorganização científica que abranja a discussão dos demais conteúdos enquanto possibilidades de organização pedagógica. Uma redefinição da atuação prática da Educação Física Escolar exige o acompanhamento de uma reorganização da formação inicial para sustentá-la.

\section{Aspectos inclusivos durante as aulas dos diferentes conteúdos}

Esta categoria associa a qualidade de participação dos alunos com deficiência nas aulas à interação social e qualificação docente.

De princípio, foi analisado o tipo de participação exercida pelos alunos com deficiência em cada um dos conteúdos trabalhados: ativa (na qual o aluno interagiu qualitativamente com o conhecimento trabalhado em aula) ou passiva (onde o aluno foi espectador da aula ou não atuou efetivamente na realização da mesma).

\begin{tabular}{lcc}
\hline \multicolumn{1}{c}{ CONTEÚDOS } & PARTICIPAÇÃO ATIVA & PARTICIPAÇ̃̃O PASSIVA \\
\hline Dança & 2 aulas & 0 aulas \\
Esporte & 8 aulas & 3 aulas \\
Jogo & 10 aulas & 2 aulas \\
\hline
\end{tabular}

Tabela - Número de aulas dos conteúdos de Educação Física nas quais os alunos com Síndrome de Down tiveram Participação Ativa ou Participação Passiva

Vale ressaltar que, permanecendo juntos todo o tempo, por iniciativa própria um aluno com deficiência seguia o comportamento do outro. Quando um dos alunos era direcionado a uma atuação passiva, o outro o acompanhava; assim como em participações ativas, um estimulava e auxiliava a participação do outro. Com o comportamento equivalente, foi permitida a construção de uma única tabela para retratar a participação de ambos.

Pelos dados apresentados, pode-se notar uma totalidade de participação ativa dos alunos com deficiência durante as aulas de Dança, a qual foi fundamentada na vivência de diferentes ritmos musicais sem a imposição de coreografias ou gestos padronizados.

Tanto nos conteúdos de Esporte quanto no de Jogo, as participações ativas ocorreram predominantemente, com os alunos com deficiência demonstrando prontidão em participar das atividades, seguindo as orientações do professor e dos demais alunos da sala.

Especificamente sobre o Esporte, em 37,5\% das aulas, houve participação passiva dos alunos com deficiência. Apesar de ser observado um esforço por parte desses alunos em realizar as atividades dentro das regras e definições estipuladas pelo professor, em 3 aulas os alunos com deficiência foram destinados à posição de auxiliar, ou deixados realizar uma atividade diferenciada, escolhida por eles próprios. Essa participação ocorreu em aulas nas quais se enfatizava as técnicas e táticas específicas do Esporte.

Já no conteúdo de Jogo, em 2 aulas a participação tornou-se passiva. Embora estivessem presentes fisicamente na quadra, esses alunos não compreenderam as regras das atividades e apenas caminharam pelo espaço, não havendo intervenção do professor.

Ainda que apresentadas ocorrências de participações passivas, nota-se a predominância de participações ativas dos alunos com deficiência; resultado este também encontrado pelo estudo de Abe e Araújo (2010). A relevância positiva desses dados pode ser elucidada quando se retoma que, segundo Ainscow (2009), para que ocorra a inclusão, o aluno deve, além de estar fisicamente no mesmo espaço que os demais, também participar 
das mesmas atividades e adquirir conhecimentos por meio destas. Por conseguinte, entende-se que estimular a participação ativa de um aluno com deficiência é um eixo indispensável para a consolidação de um trabalho inclusivo.

$\mathrm{Na}$ sequência, foi averiguado o tipo de interação entre os alunos sem deficiência em direção aos com essa condição, se positiva (aproximações com respeito) ou negativa (quando de alguma atitude de desrespeito ou rejeição):

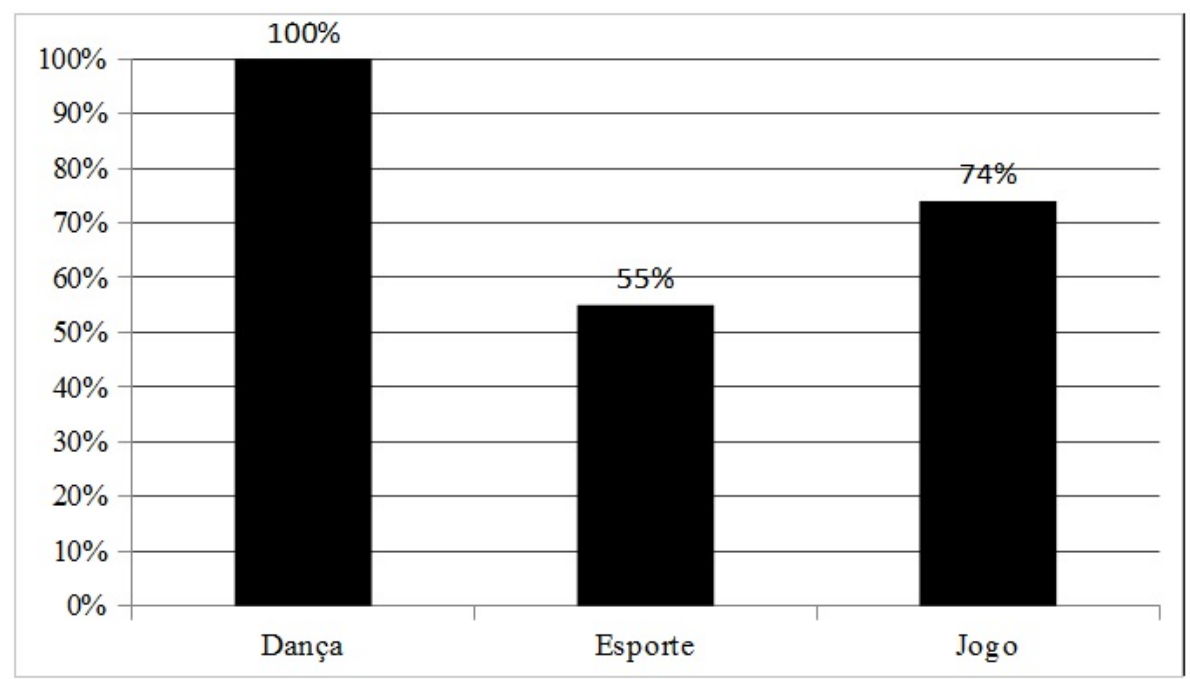

Gráfico 2 - Ocorrência, em cada conteúdo, de interações

positivas dos alunos da turma para com os alunos com deficiência.

O conteúdo de Dança, trabalhado de forma a permitir a vivência, mais uma vez mostrou ser benéfico ao estimular interações positivas em todos os momentos. Esses benefícios podem ser associados à forma de exploração docente dessa prática enquanto expressão corporal e não como busca de técnicas perfeitas. A dança, ao permitir a livre expressão e não impor gestos técnicos padronizados a serem executados, proporciona descoberta pelos alunos das possibilidades de movimentos que podem realizar, se torna um meio de comunicação e expressão que respeita a individualidade, superando padrões de criações já estabelecidos e recriando novas realidades corpóreas (Barreto, 2004).

As interações positivas ocorreram, ainda, em 55\% das aulas de Esporte e 70\% do Jogo, quando fundamentadas pelas atividades de caráter de vivência e ludicidade, aspectos que favoreceram a interação entre os alunos, com atitudes afetuosas e de auxílio dos alunos sem deficiência em direção aos com essa condição, por iniciativa própria.

Em relação às interações negativas, estas foram presenciadas nos restantes $45 \%$ das aulas de Esporte e 30\% de Jogo, quando esses conteúdos foram trabalhados exaltando a competição e a vitória, o que desencadeou atitudes de rejeição da sala em aceitarem-nos em seus times.

Resultados semelhantes foram encontrados por Fiorini (2011), ao observar que os alunos com deficiência são, de forma geral, bem aceitos e acolhidos pelos que não possuem essa condição, contudo, sofrem episódios de rejeição quando em atividades coletivas que focalizam a competição.

A aceitação e a interação social do aluno com deficiência com os demais alunos da sala apareceram como ponto crítico e fundamental para a inclusão, o que está diretamente relacionado a participar conjuntamente das mesmas atividades coletivas e de forma prazerosa (Alves \& Duarte, 2014).

Assim, uma discussão acerca da atuação docente torna pertinente uma vez que, para que o aluno usufrua de uma participação ativa nas aulas e de interações positivas com os demais, a forma de intervenção pedagógica do professor é profundamente influenciadora. 
O professor desse estudo considerou a participação dos alunos com deficiência em suas aulas, chamandoos constantemente para as atividades. Contudo, quando não acreditava na capacidade de atuação desses alunos em determinadas tarefas, alocava-os em uma posição de auxiliar ou em atividades paralelas. Já durante as interações negativas, não houve mediação para a resolução das mesmas, mas uma busca por dispersar os alunos.

Considerando também a organização pedagógica dos conteúdos, com a existência de aulas com ênfase técnica e tática, o que mostrou ser um entrave ao processo inclusivo, observa-se uma fragilidade de conhecimentos para permitir uma organização de aula de forma a permitir a participação ativa de todos, e não uma mera negação em relação ao aluno com deficiência ou ao processo inclusivo.

Estudos têm confirmado que essa ocorrência de entraves à efetivação da inclusão devido às atitudes dos professores está associada à falta de capacitação dos mesmos para uma atuação inclusiva adequada, que os conduzem às ações como negligenciar ou superproteger o aluno com deficiência e ter dificuldades em organizar atividades adequadas às diferentes capacidades (Gorgatti, 2005; Chicon, 2008; Falkenbach, 2010).

Salerno (2014) atribuiu como fator contribuinte a essa falta de capacitação a existência de fragilidades do ensino superior relatando, em seu estudo, que os discentes do curso de Educação Física não têm se sentido preparados para o trabalho com pessoas com deficiência mesmo após o acompanhamento de disciplinas referentes a essa temática. Glat \& Pletsch (2010) explicaram que essas inseguranças discentes estão associadas às fragilidades da graduação, como ao manter disciplinas destinadas a essa temática isoladas na grade curricular, a qual se desenvolve desvinculada do restante do curso de formação para a atuação docente, bem como a ausência de possibilidades de vivências reais dos alunos com essa população.

Em um momento no qual urge a necessidade em se formar docentes críticos, reflexivos e seguros para a atuação educacional, uma vinculação entre os conhecimentos teóricos com a sua aplicação na prática tornase indispensável.

Uma possibilidade dessa vinculação pode ser alcançada por meio da sugestão de Perrenoud, Thurler, Macedo, Machado \& Allessandrini (2007). Os autores propuseram que uma possível base para a melhoria na qualificação da formação inicial é a organização desta de forma que a teoria seja construída a partir dos casos observados na prática. Dessa forma, ocorre uma aprendizagem por problemas, por meio de um equilíbrio entre aportes teóricos - que antecipem e também respondam às necessidades identificadas - e as experiências práticas da sala de aula - compreendidas por fracassos, medos, dificuldades, sucessos ou alegrias durante a organização do processo de aprendizagem pelos discentes.

Ademais, algumas orientações foram elaboradas para auxílio aos professores já em atuação no contexto inclusivo. Soler (2005) e Rouse (2010) recomendaram que o professor proporcione variados tipos de auxílio aos alunos conjuntamente, como físico, verbal e gestual, demonstrando as atividades a serem realizadas para facilitar a compreensão por todos; que adapte as regras, os materiais, o espaço e sua metodologia permitindo que todos compreendam e consigam participar ativamente, independente de suas dificuldades; proporcione um tratamento o mais igualitário possível aos alunos com deficiência em relação aos demais, não o superprotegendo nem subestimando sua capacidade, estimulando-o a participar de todas as atividades de forma que este se sinta parte do grupo de alunos e auxiliando-o sim, mas apenas quando houver de fato necessidade de tal ajuda; e que estimule o desenvolvimento dos conceitos e práticas de respeito e cooperação entre os alunos.

Com a apresentação dos dados coletados, verifica-se que tem ocorrido uma reorganização da prática da Educação Física, incorporando as novas definições conteudinais da área aos ideais educacionais inclusivos estabelecidos.

Devido às características históricas e políticas da Educação Física brasileira, a qual se sucumbiu aos ideais militaristas, higienistas, eugenistas e esportivizadores, esta, em muitos momentos, acentuou as diferenças no ambiente escolar, excluindo os menos habilidosos, os com desvantagens físicas, obesos ou tímidos. Conforme 
seus objetivos, finalidades e funções foram repensados e reconstruídos, a redefinição da Educação Física Escolar foi delineada abarcando a participação de todos em suas aulas.

Segundo Fiorini (2011), há um indicativo de mudança da Educação Física em direção a superar a sua história tecnicista e excludente e em favorecer os ideais inclusivos em sua prática, com professores cada vez mais buscando formas de permitir a participação de todos de forma prazerosa e construtiva.

Nesse momento, almeja-se consolidar uma Educação Física Escolar com seus conteúdos orientados por um caráter de vivência e construção de conhecimento sócio-histórico-cultural, fundamentados em uma perspectiva inclusiva na qual todos são respeitados e valorizados em sua diversidade (Brasil, 1998). Algumas considerações sobre cada um dos temas já tem sido desenhadas academicamente e politicamente, podendo ser citadas como forma de sustentar o trabalho docente:

- Dança: Com movimentos alicerçados em expressões de emoções e sentimentos, no ambiente escolar podem ser explorados os aspectos histórico-sociais de cada tipo de dança, a percepção do ritmo pessoal e coletivo, a relação de espaço e tempo, a expressão por meio de códigos e gestos e a consciência referente aos próprios limites corporais assim como as possibilidades de superação destes (Brasil, 1998).

A Dança apresenta-se como uma facilitadora da inclusão ao proporcionar ludicidade, estímulo à participação de todos, vivência cultural com conscientização e criação própria de movimentos corporais e liberdade de expressão individual. Winnick (2004) ressaltou, ainda, que para as pessoas com deficiência pode proporcionar a autodescoberta, melhora na autoestima e imagem corporal, interação social, o desenvolvimento auditivo, visual, cinestésico, criativo e do equilíbrio, bem como diminuir a ansiedade e uma possível depressão.

- Esporte: Se a partir da década de 1970 foi explorado no cenário escolar quase como conteúdo único, por meio da reprodução do modelo de esporte de alto desempenho baseado na exclusão e desigualdade, a transformação desse cenário ganhou delimitação com a elaboração de novas teorias para a área. Bracht (1992) corroborou com tais transformações ao diferenciar o esporte da escola - o qual deve ser desenvolvido com adaptação de regras e técnicas com finalidade educacional e formação humana - da presença do esporte de alto rendimento na escola.

O esporte enquanto conteúdo educacional não deve se restringir ao ensino e execução das técnicas e táticas de modalidades esportivas, mas construir conhecimentos históricos e socioculturais de forma crítico-reflexiva, conjuntamente à vivência das diversas modalidades, possibilitando um desenvolvimento global dos alunos (Coletivo de autores, 1992; Brasil, 1998; Paes \& Balbino, 2005).

Assim, não pode ser concluído que o esporte é estimulador da exclusão, mas sim que a forma de trabalhar mecanicamente e competitivamente um conteúdo propicia a rejeição das diferenças e a dificuldade na participação de todos. Por outro lado, pode estimular o processo inclusivo com o desenvolvimento de um trabalho educacional alicerçado nos ideais de respeito, aceitação e valorização das diferenças (Carvalho \& Araújo, 2015).

Esse conteúdo pode contribuir com a inclusão ao, para os alunos com deficiência, melhorar as suas condições e capacidades físicas, estimular a independência e a superação; e, para todos os alunos, ao melhorar as relações interpessoais, estimular a socialização, os aspectos afetivos e valores humanos (Winnick, 2004).

- Jogo: Tendo por finalidade o alcance de um objetivo, em um limite de tempo e espaço, é um fator de desenvolvimento ao permitir, por meio da ludicidade e imaginação, a compreensão das regras sociais, a ampliação da capacidade de tomada de decisão e o trabalho em equipe com construções coletivas de soluções às situações de jogo (Coletivo de autores, 1992; Brasil, 1998). Pode atuar, ainda, como uma ferramenta facilitadora da inclusão por proporcionar situações de afetividade e interação, estimulando a superação da timidez e a maior participação do aluno com alguma condição de deficiência, proporcionando a cooperação entre todos do grupo em prol do alcance de um objetivo, 
fortalecendo os laços de união e respeito, além de permitir maior flexibilidade das regras, do local, do material e do próprio objetivo final para a participação ativa de todos (Gil, Scheeren, Lemos \& Ferreira, 2002).

- Luta: Segundo os PCN (Brasil, 1998/2000), na luta há um conjunto de movimentos corporais empregados em uma disputa com um oponente, fundamentada em ações de ataque e defesa. Enquanto conteúdo educacional, pode-se explorar o conhecimento a respeito dos diversos princípios de filosofia que regem as práticas, a reflexão sobre a diferença entre a luta e a violência social, o conhecimento das capacidades físicas e habilidades motoras das diversas modalidades e a vivência das técnicas, táticas e regras.

Segundo Gomes (2008), a metodologia mais adequada para o trabalho com esse conteúdo visando à inclusão escolar é aquela na qual o professor oferece diferentes meios para executar os movimentos ao invés de padronizar uma única forma como a mais adequada, enfatizando os fundamentos de ataque e defesa antes da vivência das técnicas.

- Ginástica: O Coletivo De Autores (1992) e os PCN (Brasil, 1998) sugeriram que o professor trabalhe esse conteúdo de forma a conscientizar os alunos sobre a presença dos fundamentamos da ginástica no dia-a-dia; as sensações afetivas e cinestésicas provocadas pelos movimentos; com a organização de práticas individuais e coletivas; o conhecimento das diferentes formas, capacidades e habilidades físicas e técnicas ginásticas; e a organização de apresentações; sempre fundamentados na compreensão sobre a transformação da ginástica durante o decorrer histórico e suas diferenças culturais.

Mayeda e Araújo (2004) ressaltaram que a ginástica pode explorar o desenvolvimento da criatividade e da expressão como uma forma de cooperação e afetividade em substituição à competição exacerbada, estimulando a autodescoberta de possibilidades corporais de movimentos de forma respeitosa às características de cada um, o desenvolvimento da imagem corporal e a socialização por meio de vivências e criações em grupos, facilitando a inclusão por meio de atividades não segregacionistas.

Podem ainda ser explorados, os conteúdos em sua versão adaptada, como o esporte adaptado, dança adaptada e luta adaptada, proporcionando conhecimento e vivência dos educandos a respeito dessas modalidades específicas para pessoas com deficiência, além da estimulação de percepções diferentes das comumente vivenciadas.

A efetivação da inclusão na Educação Física exige, nesse momento, o abandono dos resquícios tecnicistas e esportivizadores daquelas práticas enfatizadoras do desenvolvimento de gestos motores eficientes, as quais dificultaram o processo inclusivo; e abertura às aulas com diversificação de conteúdo com caráter de vivência e construção de conhecimento, que se mostraram facilitadores da inclusão. Para isso, a formação docente torna-se ponto primordial para capacitar o professor a explorar os diferentes conteúdos da Educação Física de forma a adequá-los às diferentes necessidades e permitir a participação ativa de todos.

Consolidar uma Educação Física Escolar inclusiva depende, não apenas dos conhecimentos sobre as pessoas com deficiência e suas necessidades e capacidades, mas também sobre as particularidades da Educação Física enquanto área educacional.

\section{Conclusões}

Com esse estudo foi possível verificar a existência de um caminhar concomitante de busca pela consolidação das novas teorias da Educação Física Escolar na prática e de adequação às novas orientações inclusivas. Para essa inclusão se efetivar, há a necessidade da superação do ainda presente caráter de treinamento esportivo das habilidades, que mostrou ser prejudicial à inclusão, para dar lugar à vivência e construção de conhecimentos sobre os diversos conteúdos de forma lúdica - fator estimulador do processo inclusivo. 
O fato de apenas uma escola ter sido observada limita a generalização das reflexões, mas, por outro lado, permite um aprofundamento sobre um local específico que pode mostrar fatores possíveis de ocorrerem em outros locais que poderiam passar despercebidos em pesquisas de maior quantidade de locais. Por conseguinte, nesse momento, necessita-se de novas ações para que o tema continue a ser retratado com cada vez maior profundidade, tanto para superar possíveis lacunas presentes nesse próprio estudo quanto para discorrer sobre dificuldades na realidade que foram identificadas por meio da realização do mesmo:

- Realização de pesquisas orientando as possibilidades de organização pedagógica com os conteúdos de Dança, Ginástica e Luta, associados aos ideais inclusivos;

- Elaboração de estudos analisando a relação inclusiva de outras condições de deficiência, além da Síndrome de Down observada nesse estudo, com os conteúdos da Educação Física, e;

- Reformulação da formação inicial e continuada de forma a estimularem a constituição de um docente crítico e reflexivo perante a nova realidade da Educação Física Escolar, em relação a sua diversidade de possibilidades de conteúdos e a sua orientação inclusivista, para que o professor se torne pró-ativo nas ações de reflexão e contínua reconstrução de sua prática segundo as diferentes necessidades e realidades que se apresentarem.

Buscando cada vez maior qualificação para a atuação adequada perante as diferentes necessidades dos alunos, a Educação Física Escolar tem, por meio da inclusão, um estímulo e uma oportunidade para se qualificar para atender a todos os alunos, e não apenas para os com deficiência. O período vivenciado ainda é de transformação, mas em direção a um caminho de construção de uma prática com maior qualidade, com conteúdos vinculados a um desenvolvimento global de todos os alunos e de forma adequada respeitosa às suas diversidades.

\section{REFERÊNCIAS BIBLIOGRÁFICAS}

Abe, P.B., \& Araújo, R.C.T. (2010). A participação escolar de alunos com deficiência na percepção de seus professores. Revista Brasileira de Educação Especial, 16(2), 283-296.

Ainscow, M. (2009). O que significa inclusão?Entrevista. Centro de Referencia em Educação Mario Covas / SEE-SP. Recuperado em 13 de fevereiro, 2017. Recuperado de: http://www.crmariocovas.sp.gov.br/ees_a.php?t=002.

Alves, M. L. T., \& Duarte, E. (2014). A percepção dos alunos com deficiência sobre a sua inclusão nas aulas de Educação Física escolar: um estudo de caso. Revista Brasileira de Educação Física e Esporte, 28(2), 329-38.

Ayoub, E. (2003). A Ginástica Geral e Educação Física Escolar. Campinas, Brasil: UNICAMP.

Barreto, D. (2004). Dança, ensino, sentidos e possibilidades na escola. Campinas, Brasil: Autores Associados.

Bracht, V. (1992). Aprendizagem social e Educação Física. Porto Alegre: Magister.

Carvalho, A. O., Darido, S. C., \& Impolcetto, F. M. (2015). Análise do conteúdo de ginástica nos currículos estaduais brasileiros. Arquivos em Movimento, 11(1), 54-73.

Carvalho, C. L., \& Araújo, P. F. (2015). Esporte: um conteúdo excludente ou inclusivo na educação física escolar? Conexões, 13(4), 100-118.

Castellani Filho, L. (1991). Educação Física no Brasil: a história que não se conta. 2.ed.. Campinas, Brasil: Papirus.

Chicon, J. F. (2008). Inclusão e exclusão no contexto da educação física escolar. Movimento, 14(1), 13-38.

Coletivo de Autores. (1992). Metodologia do Ensino da Educação Física. São Paulo, Brasil: Cortez.

Constituição da República Federativa do Brasil de 1988. (1988). Brasília. Recuperado em 14 janeiro, 2017, de http:// www.planalto.gov.br/ccivil_03/Constituicao/Constituicao.htm.

Correia, W. R., \& Franchini, E. (2010). Produção acadêmica em lutas, artes marciais e esportes de combate. Motriz, 16(1), 01-09. 
Declaração de Salamanca. Sobre Princípios, Politicas e Práticas na Area das Necessidades Educativas Especiais. (1994). Brasília. Recuperado em 12 janeiro, 2017, de portal.mec.gov.br/seesp/arquivos/pdf/salamanca.pdf.

Falkenbach, A. P. (2010). Inclusão: perspectivas para as áreas da educação física, saúde e educação. Jundiaí, Brasil: Fontoura.

Fiorini, M. L. S. (2011). Concep̧̧ão do professor de educação física sobre a inclusão do aluno com deficiência. (Dissertação de Mestrado). Universidade Estadual Paulista, Marília, SP, Brasil.

Gil, J. P.A., Scheeren, C., Lemos, H. D. D., \& Ferreira, S. M. (2002). O significado do jogo e do brinquedo no processo inclusivo: conhecendo novas metodologias no cotidiano escolar. Revista Educação Especial, 1(20), 75-88.

Glat, R., \& Pletsch, M. D. (2010). O papel da Universidade no contexto da política de Educação Inclusiva: reflexões sobre a formação de recursos humanos e a produção de conhecimento. Revista Educação Especial, 23(38), 345-356.

Góis Junior, E. (2013). Ginástica, higiene e eugenia no projeto de nação brasileira: Rio de Janeiro, século XIX e início do século XX. Movimento, 19(1), 139-159.

Gomes, M. P. (2008). Procedimentos pedagógicos para o ensino de Lutas: contextos e possibilidades. (Dissertação de Mestrado). Universidade Estadual de Campinas, Campinas, SP, Brasil.

Gorgatti, M. G. (2005). Educação física escolar e inclusão: uma análise a partir do desenvolvimento motor e social de adolescentes com deficiência visual e das atitudes dos professores. (Tese de Doutorado). Universidade de São Paulo, São Paulo, SP, Brasil.

Gorgatti, M., \& Rose Junior, R. (2009). Percepções dos Professores Quanto à Inclusão de Alunos com Deficiência em Aulas de Educação Física. Movimento, 15(02), 119-140.

Jannuzzi, G. M. (1992). A luta pela Educação do Deficiente Mental no Brasil. Campinas, Brasil: Autores Associados.

Kassar, M. C. M. (2011). Percursos de uma política brasileira de Educação Especial.Revista Brasileira de Educação Especial, 17(1), 41-58.

Lei $n^{\circ}$ 9.394, de 20 de dezembro de 1996. (1996). Brasília. Recuperado em 14 de Janeiro, 2017, de portal.mec.gov.br/ seesp/arquivos/pdf/lei9394_ldbn1.pdf.

Lei n. 10.098, de 19 de dezembro de 2000. (2000). Brasília. Recuperado em 18 de Janeiro, 2017, de http://www.plan alto.gov.br/ccivil_03/leis/L10098.htm.

Lein ${ }^{\circ} 10.172$, de 9 de janeiro de 2001. (2001a). Brasília. Recuperado em 14 de Fevereiro, 2017, de www.planalto.gov.br/ ccivil_03/leis/leis_2001/110172.htm.

Lei $n^{\circ}$ 10.328, de 12 de dezembro de 2001. (2001b). Brasília. Recuperado em 18 de Janeiro, 2017, de www.planalto.gov.br/ccivil_03/leis/LEIS_2001/L10328.htm.

Lei no 13.005, de 25 de junho de 2014. (2014). Brasília. Recuperado em 14 de janeiro, 2017, de www.planalto.gov.br/ ccivil_03/_ato2011-2014/2014/lei/113005.htm.

Linhares, M. A. (2009). Militares e educadores na Associação Brasileira de Educação: circulação de interesses em torno de um projeto para a educação física nacional (1933-1935). Educar em Revista, 33(1), 75-91.

Ludke, M., \& André, M. E. D. A. (1986). Pesquisa em educação: abordagens qualitativas. São Paulo, Brasil: EPU.

Manzini, E. J. (2002). Participação em aulas de educação física: o que alunos com deficiência visual e física relatam. Coleção prata da casa, V. esp. (1), 81-85.

Matos, J. M. C., Schneider, O., Mello, A. S., Ferreira Neto, A., \& Santos, W. (2013).A produção acadêmica sobre conteúdos de ensino na educação física escolar. Movimento, 19(02), 123-148.

Mayeda, S., \& Araújo, P. F. (2004). Uma proposta de ginástica geral para deficientes físicos. Movimento \& Percep̧̧ão, 4(4/5), 55-73.

Mazzarino, J. M., Falkenbach, A. \& Rissi, S. (2011). Acessibilidade e inclusão de uma aluna com deficiência visual na escola e na educação física. Revista Brasileira de Ciências do Esporte, 33(1), 87-102. Recuperado em 14 de janeiro, 2017, de https://dx.doi.org/10.1590/S0101-32892011000100006 
Meireles-Coelho, C., Izquierdo, T., \& Santos, C. (2007, abril). Educação para todos e sucesso de cada um: do Relatório Warnock à Declaração de Salamanca. Actas do IX Congresso da Sociedade Portuguesa de Ciências da Educação. Funchal, Ilha da Madeira, Portugal, 12.

ONU. Resolução n 217, de 10 de dezembro de 1948. (1948). Recuperado em 13 de fevereiro, 2017, de http://app;cre a-rj.org.br/poralcreav2midia/documentos/resolucaoonu217aiii.pdf.

Paes, R. R., \& Balbino, H. F. (2005). Pedagogia do esporte: contextos e perspectivas. Rio de Janeiro, Brasil: Guanabara Koogan.

Parâmetros curriculares nacionais: Educação física. (1998). Brasília. Recuperado em 14 de janeiro, 2017, de portal.mec.gov.br/seb/arquivos/pdf/fisica.pdf.

Perrenoud, P., Thurler, M. G., Macedo, L., Machado, N. J., \& Allessandrini, C. D. (2007). As competênciaspara ensinar no século XXI: a formação dos professores e o desafio da avaliação. Porto Alegre, Brasil: Artmed.

Rouse, P. (2010). Inclusion on physical education: fitness, motor and social skills for students of all abilities. Champaign: Human Kinetcs

Salerno, M. B. (2009) Interação entre alunos com e sem deficiência na educação física escolar: validação de instrumento. Dissertação (Mestrado em Educação Física) - Faculdade de Educação Física, Universidade Estadual de Campinas, Campinas, $124 \mathrm{p}$.

Salerno, M. B. (2014). A informação em Educação Física e o trabalho com a pessoa com deficiência: percepção discente. (Tese de Doutorado). Universidade Estadual de Campinas, Campinas, SP, Brasil.

Seabra Júnior, L. (2006). Inclusão, necessidades especiais e Educação Física: considerações sobre a ação pedagógica no ambiente escolar. (Dissertação de Mestrado). Universidade Estadual de Campinas, Campinas, SP, Brasil.

Silva, O. M. da. (1987). A pessoa deficiente na história do mundo de ontem e de hoje. São Paulo, Brasil: CEDAS.

Silva, R. F., Seabra Junior, L., \& Araújo, P. F.(2008). Educação física adaptada no Brasil: da historia à inclusão educacional. São Paulo, Brasil: Phorte.

Soler, R. (2005). Educação Física Inclusiva: em busca de uma escola plural. Rio de Janeiro, Brasil: Sprint.

Souza Júnior, M., Barboza, R. G., Lorenzini, A. R., Guimarães, G., Sayone, H., Ferreira, R. C., Pereira, E. L., França, D., Tavares, M., Lindoso, R. C., \& Sousa, F. C. (2011). Coletivo de Autores: a cultura corporal em questão. Revista Brasileira de Ciências do Esporte, Florianópolis, 33(2), 391-411.

Winnick, J. P. (2004). Educação física e esportes adaptados. Barueri, Brasil: Manole.

Recepção: 08 Setembro 2017

Aprovação: 21 Dezembro 2017

La aceptación de colaboraciones por parte de la revista implica la cesión no exclusiva de los derechos patrimoniales de los autores a favor del editor, quien permite la reutilización, luego de su edición (postprint), bajo Licencia Creative Commons Atribución-NoComercial-CompartirIgual 4.0 Internacional (https:// creativecommons.org/licenses/by-nc-sa/4.0/).

CC BY-SA 